\title{
Chronic Obstructive Pulmonary Disease with Incidence of Heart Failure and Its Influencing Factors
}

\author{
Andry Wahyudi Agus ${ }^{1,2 *(D)}$, Adrianison ${ }^{1,2}$, Dyah Siswanti ${ }^{3}$, Faisal Yunus ${ }^{4}$, Zahtamal $^{5}$ \\ ${ }^{1}$ Department of Pulmonology and Respiratory Medicine, Faculty of Medicine, University of Riau, Pekanbaru, Indonesia. \\ ${ }^{2}$ Department of Pulmonology and Respiratory Medicine, Arifin Achmad General Hospital, Pekanbaru, Indonesia. \\ ${ }^{3}$ Department of Cardiology and Vascular Medicine, Arifin Achmad General Hospital, Pekanbaru, Indonesia. \\ ${ }^{4}$ Department of Pulmonology and Respiratory Medicine, Faculty of Medicine, Universitas Indonesia, Jakarta, Indonesia. \\ ${ }^{5}$ Department of Public Health, Faculty of Medicine, University of Riau, Pekanbaru, Indonesia.
}

\section{ARTICLE INFO}

Article history:

Received 19 July 2021

Received in revised form 12 January

2022

Accepted 21 January 2022

Available online 30 January 2022

\section{Keywords:}

COPD,

Echocardiography,

Heart failure,

Human \& medicine,

Pulmonary hypertension.

\begin{abstract}
Introduction: Chronic obstructive pulmonary disease (COPD) is often associated with cardiovascular disease because it has the same risk factors as smoking. One of the cardiovascular complications in COPD is heart failure. Echocardiography examination is a tool to evaluate changes of the heart both anatomically and functionally. This study aimed to determine the relationship between COPD and heart failure by echocardiography examination in stable COPD patients.

Methods: This was a descriptive-analytic study using a cross-sectional design for COPD patients who visited the Lung Polyclinic of Arifin Achmad Hospital, Pekanbaru, Riau, which was conducted from November 2020 to March 2021. Subjects who met the inclusion criteria were examined by spirometry, chest X-rays, and echocardiography.

Results: In this study, there were 66 stable COPD subjects. It was found that $15.2 \%$ of subjects had right heart failure based on the tricuspid annular plain systolic excursion (TAPSE) assessment and 7.6\% of the subjects had left heart failure based on the left ventricular ejection fraction $(\mathrm{LVEF})$ value. Right ventricular dilatation $(p=0.000)$, right ventricular dysfunction $(\mathrm{p}=0.005)$, and increased probability of pulmonary hypertension $(\mathrm{PH})(\mathrm{p}=0.000)$ were significantly associated with a decrease in the first second forced expiratory volume (FEV1).

Conclusion: The severity of COPD with FEV1 $<50 \%$ had a significant relationship with dilatation, dysfunction of right ventricular, and increased the probability of incidence of $\mathrm{PH}$ based on parameters tricuspid regurgitation (TR). A history of exacerbations $\geq 2$ times in a year caused right ventricular dilatation, decreased right ventricular function, and increased the probability of $\mathrm{PH}$.
\end{abstract}

\section{INTRODUCTION}

Chronic obstructive pulmonary disease (COPD) is a global health problem and is the fourth leading cause of death in the world. Many people die due to COPD or its complications. ${ }^{1}$ The development of COPD causes progressive airflow limitation, air trapping, and pulmonary hyperinflation as well as increased pulmonary vascular pressure. ${ }^{1,2}$ In addition to causing pulmonary abnormalities, COPD also has an impact on other organs known for systemic complications and comorbidity which contribute to prognosis, functional ability, the severity of COPD, and mortality. ${ }^{3}$ COPD has blood vessels causing pulmonary hypertension $(\mathrm{PH})$, cor pulmonary, right ventricular dysfunction, and left ventricular dysfunction. The mortality rate in COPD patients increases due to the involvement of cardiovascular disorders such as ischemic heart disease. ${ }^{4}$

Echocardiography examination is a non-invasive examination procedure which can be used to evaluate cardiac changes both anatomically and functionally tricuspid such as assessing right ventricular function, right ventricular filling pressure, tricuspid regurgitation (TR), left ventricular function, and cardiac valve. ${ }^{5,6}$ This assessment is very important to determine cardiac changes which occur as early as possible in stable COPD patients, hence the selection and administration of appropriate therapy can be started, can be assessed

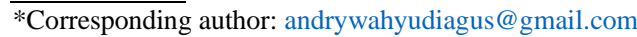


prognosis, and can be given secondary prevention measures to improve the patient's quality of life. This study aimed to determine the prevalence of heart failure in stable COPD patients and to see the relationship between severity of COPD based on Global Initiative for Chronic Obstructive Lung Disease (GOLD) with dimension, function, and cardiac pressure.

\section{METHODS}

This was a descriptive-analytic study with crosssectional design which was conducted on stable COPD patients who visited the Lung Polyclinic of Arifin Achmad Hospital, Pekanbaru, Riau. This study was conducted from November 2020 to March 2021. This study had passed an ethical review and had been approved by the Ethical Review Board for Medicine and Health Research, Faculty of Medicine, University of Riau (No. B/004/UN19.5.1.1.8/UEPKK/2021).

The inclusion criteria consisted of all mild to severe COPD patients, male or female who visited the Lung Polyclinic of Arifin Achmad Hospital, Pekanbaru, Riau and were willing to participate in this study by signing the informed consent. Exclusion criteria were patients with acute coronary syndrome, moderate to severe mitral stenosis, all pulmonary diseases other than COPD as evidenced by chest X-ray with abnormalities in the lung parenchyma and pleura, and poor echocardiography window.

All subjects who met the inclusion criteria underwent examinations such as anamnesis, physical examination, spirometry, chest X-ray, blood pressure. measurement, electrocardiography, and echocardiography. A spirometry examination was performed to assess the severity of COPD based on the 2019 GOLD. The patient also performed a chest X-ray examination to rule out lung diseases other than COPD. Then the patient was sent to the Polyclinic Cardiology for tests to measure blood pressure, electrocardiography, and echocardiography. Echocardiography examination was performed to assess the dimensions of RV and LV, right ventricular function through the parameters of tricuspid annular plain systolic excursion (TAPSE) $(<1.7$ $\mathrm{mm})$, and right ventricular function through the ejection fraction value ( $\mathrm{LVEF}<40 \%$ ).

The data obtained was analyzed with statistical package for social science (SPSS) software 2.6. Data analysis in this study used chi-square because the variables being compared were categorical scales. The numerical data for each variable was calculated as mean and standard deviation. The data which was and was not categorized was normally distributed using medians and maximum and minimum values. Bivariate data were tested with chi-square and if they did not meet the requirements, then Fisher's test was performed. The analysis was continued with a logistic regression test for the bivariate test results that met the multivariate requirements, namely $\mathrm{p}<0.25$.

\section{RESULTS}

The total sample collected during the study period and had met the inclusion criteria was 66 stable COPD subjects. Male patients were the largest subject at $93.9 \%$ and the median age of the subject in the study was 65 years old with the youngest subject age in this study being 45 years old and the oldest was 84 years old. The severity of COPD based on GOLD was found to be $56.1 \%$ GOLD II, 39.4\% GOLD III, and $4.5 \%$ GOLD IV. The echocardiographic findings of the subjects found that $22.7 \%$ had RV dilatation, $19.7 \%$ had $\mathrm{LV}$ dilatation, $15.2 \%$ had RV dysfunction, and $7.6 \%$ had LV dysfunction. The basic characteristics and echocardiographic findings of the subjects are shown in Table 1.

\section{Relationship of COPD severity with dimensions of cardiac ventricles}

In this study, it was found that $22.7 \%$ of subjects had RV dilatation and $19.7 \%$ of subjects had LV dilatation as shown in Table 2. Dilatation of RV was found in GOLD II 5.4\%, GOLD III 38.5\%, and GOLD IV $100 \%$ in COPD subjects. The severity of COPD was significantly associated with RV dilatation $(p=0.000)$. Subjects were then divided into two groups, namely the mild-moderate COPD group (FEV1 $\geq 50 \%$ pred) and the severe COPD group (FEV1 $<50 \%$ pred). Dilatation of $\mathrm{RV}$ was found to be $44.8 \%$ in FEV1 group $<50 \%$ pred $(p=0.000)$ and a prevalence ratio (PR) of $8.3(95 \% \mathrm{CI}=$ 2.03-33.87) which means that the prevalence of $\mathrm{RV}$ dilatation was found to be 8.3 times more in the severe COPD group than in the mild COPD group. The leftsided ventricular showed no significant relationship between the degree of severity in COPD with dilatation of LV ( $p=0.300$ and $p=0.623)$.

\section{Relationship of COPD severity with functions of cardiac ventricles}

Dysfunction of RV was found in $15.2 \%$ and dysfunction of LV in $7.6 \%$ of stable COPD subjects as shown in Table 3. Dysfunction of RV was found in GOLD II $2.7 \%$, GOLD III $23.1 \%$, and GOLD IV $100 \%$. This shows that the severity of COPD is significantly associated with decreased RV function $(p=0.000)$. Dysfunction of RV was also found in $31 \%$ of FEV1 group $<50 \%$ pred with $p=0.005$ and PR 11.5 (1.5485.53). This means that the prevalence of dysfunction of $\mathrm{RV}$ was found to be 11.5 times more in the severe COPD group than in the mild-moderate COPD group. In the left-sided ventricular, there was no significant relationship between the severity of COPD and the dysfunction of $\operatorname{LV}(p=0.143$ and $p=0.222)$. 
Table 1. Basic characteristics and echocardiography findings in stable COPD patients

\begin{tabular}{|c|c|c|c|}
\hline $\begin{array}{l}\text { Charac } \\
\text { patients }\end{array}$ & ristics of $\mathrm{CC}$ & $\begin{array}{c}\text { Number of } \\
\text { Case (n) }\end{array}$ & $\begin{array}{c}\text { Percentage } \\
(\%)\end{array}$ \\
\hline Gender & & & \\
\hline & $\begin{array}{l}\text { Male } \\
\text { Female }\end{array}$ & $\begin{array}{c}62 \\
4\end{array}$ & $\begin{array}{c}93.9 \\
6.1\end{array}$ \\
\hline Age & & & \\
\hline & $\geq 65$ years old & 35 & 53 \\
\hline & $<65$ years old & 31 & 47 \\
\hline Smoking & history & & \\
\hline & Former smoker & 58 & 87.9 \\
\hline & Active smoker & 5 & 7.6 \\
\hline & Not a smoker & 3 & 4.5 \\
\hline Brinkma & Index & & \\
\hline & Mild & 6 & 9.1 \\
\hline & Moderate & 8 & 12.1 \\
\hline & Severe & 52 & 78.8 \\
\hline
\end{tabular}

Exacerbation and number of

exacerbation in 1 year

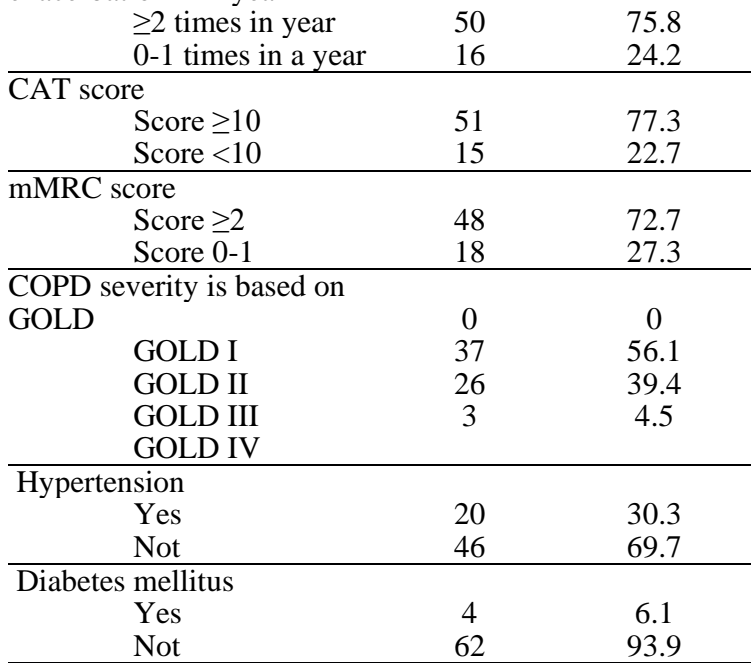

Characteristics of echocardiography findings in COPD subjects

\begin{tabular}{ccc}
\hline RV dimensions & & \\
RV dilatation & 15 & 22.7 \\
Normal & 51 & 77.3 \\
\hline LV dimensions & & \\
LV dilatation & 13 & 19.7 \\
\hline
\end{tabular}

\begin{tabular}{ccc}
\hline $\begin{array}{l}\text { Characteristics of COPD Number of } \\
\text { patients }\end{array}$ & $\begin{array}{c}\text { Percentage } \\
\text { Case (n) }\end{array}$ \\
\hline Normal & 53 & 80.3 \\
\hline RV function (TAPSE) & 10 & 15.2 \\
Decreased & 56 & 84.8 \\
Normal & 5 & 7.6 \\
\hline LV function (LVEF) & 61 & 92.4 \\
Decreased & & \\
Normal & 28 & 42.4 \\
Tricuspid valve & 38 & 57.6 \\
Regurgitation & & \\
Normal & 9 & 13.6 \\
Degree of TR & 16 & 24.2 \\
Mild TR & 3 & 4.6 \\
Moderate TR & 38 & 57.6 \\
Severe TR & & \\
Normal & 12 & 18.2 \\
Regurgitation & 54 & 81.8 \\
\hline Normal & & \\
Mitral valve & 8 & 12.1 \\
Pulmonary valve & 87.9 \\
Regurgitation & 58 & \\
Normal & 4 & 6.1 \\
\hline Aortic valve & & \\
Regurgitation & 62 & 30.3 \\
Normal & 20 & 69.7 \\
\hline Pulmonary artery in diameter & \\
Dilatation & 46 & \\
Normal & & \\
\hline & & \\
\hline
\end{tabular}

\section{Relationship of severity COPD with the probability of} PH based on TR

A total of $43.4 \%$ of subjects experienced TR, namely $13.6 \%$ mild TR, $24.2 \%$ moderate TR, and $4.6 \%$ severe TR. Based on the findings of TR, it was found that there were $25 \%$ of subjects with low probability $\mathrm{PH}$, $32.1 \%$ with intermediate probability $\mathrm{PH}$, and $42.9 \%$ with high probability $\mathrm{PH}$. Based on the severity of COPD, it was found $18.9 \%$ in GOLD II, $64.3 \%$ in GOLD III, and $100 \%$ in GOLD IV. This shows that the severity of

Table 2. Relationship of severity of COPD with dimensions cardiac ventricular

\begin{tabular}{|c|c|c|c|c|c|c|}
\hline Severity of COPD & $\begin{array}{c}\text { RV dilatation } \\
(\mathrm{n}=15)\end{array}$ & $\mathrm{p}$ & PR $(95 \% \mathrm{CI})$ & $\begin{array}{l}\text { LV dilatation } \\
\quad(\mathrm{n}=13)\end{array}$ & $\mathrm{p}$ & PR (95\% CI) \\
\hline GOLD IV $(\mathrm{n}=3)$ & $3(100 \%)$ & 0.000 & & 0 & 0.300 & \\
\hline GOLD III (n = 26) & $10(38.5 \%)$ & & & $7(26.9 \%)$ & & \\
\hline GOLD II $(n=37)$ & $2(5.4 \%)$ & & & $6(16.2 \%)$ & & \\
\hline $\begin{array}{l}\text { FEV1 }<50 \% \text { pred } \\
(\mathrm{n}=29)\end{array}$ & $13(44.8 \%)$ & 0.000 & $\begin{array}{c}8.3 \\
(2.03-33.87)\end{array}$ & $7(24.1 \%)$ & 0.623 & $\begin{array}{c}1.5 \\
(0.56-3.95)\end{array}$ \\
\hline $\begin{array}{l}\text { FEV } 1 \geq 50 \% \text { pred } \\
(\mathrm{n}=37)\end{array}$ & $2(5.4 \%)$ & & & $6(16.2 \%)$ & & \\
\hline
\end{tabular}

Table 3. Relationship of severity of COPD with cardiac ventricular functions

\begin{tabular}{|c|c|c|c|c|c|c|}
\hline Severity of COPD & $\begin{array}{c}\text { RV dysfunction } \\
(\mathrm{n}=10)\end{array}$ & $\mathrm{p}$ & PR $(95 \%$ CI $)$ & $\begin{array}{l}\text { LV dysfunction } \\
(\mathrm{n}=5)\end{array}$ & $\mathrm{p}$ & PR $(95 \% \mathrm{CI})$ \\
\hline GOLD IV $(n=3)$ & $3(100 \%)$ & 0.000 & & 0 & 0.143 & \\
\hline GOLD III $(n=26)$ & $6(23.1 \%)$ & & & $4(15.4 \%)$ & & \\
\hline GOLD II $(n=37)$ & $1(2.7 \%)$ & & & $1(2.7 \%)$ & & \\
\hline $\begin{array}{l}\text { FEV1 }<50 \% \text { pred } \\
(\mathrm{n}=29)\end{array}$ & $9(31 \%)$ & 0.005 & $\begin{array}{c}11.5 \\
(1.54-85.53)\end{array}$ & $4(13.8 \%)$ & 0.222 & $\begin{array}{c}5.1 \\
(0.60-43.23)\end{array}$ \\
\hline $\begin{array}{l}\text { FEV } 1 \geq 50 \% \text { pred } \\
(\mathrm{n}=37)\end{array}$ & $1(2.7 \%)$ & & & $1(2.7 \%)$ & & \\
\hline
\end{tabular}


Table 4. Relationship of COPD severity based on GOLD with a degree of probability of PH

\begin{tabular}{|c|c|c|c|c|}
\hline \multirow[b]{2}{*}{ Subject Characteristics } & \multicolumn{3}{|c|}{ Probability of PH } & \multirow[b]{2}{*}{$\mathrm{p}$} \\
\hline & $\begin{array}{l}\text { High prob } \\
\mathrm{n}=12\end{array}$ & $\begin{array}{c}\text { Intermediate prob } \\
n=9\end{array}$ & $\begin{array}{c}\text { Low prob } \\
n=7\end{array}$ & \\
\hline GOLD IV $(n=3)$ & $3(100 \%)$ & 0 & 0 & 0.000 \\
\hline GOLD III (n = 26) & $8(30.8 \%)$ & $7(26.9 \%)$ & $3(11.5 \%)$ & \\
\hline GOLD II $(n=37)$ & $1(2.7 \%)$ & $2(5.4 \%)$ & $4(10.8 \%)$ & \\
\hline
\end{tabular}

Table 5. Relationship of COPD based on severity of airflow limitation with probability of PH

\begin{tabular}{|c|c|c|c|c|}
\hline \multirow[b]{2}{*}{ Subject Characteristics } & \multicolumn{2}{|c|}{ Probability of $\mathrm{PH}$} & \multirow[b]{2}{*}{$\mathrm{p}$} & \multirow{2}{*}{$\begin{array}{c}\mathrm{PR} \\
(95 \% \mathrm{CI})\end{array}$} \\
\hline & $\begin{array}{c}\text { Yes } \\
\mathrm{n}=28\end{array}$ & $\begin{array}{c}\text { Normal } \\
\mathrm{n}=38\end{array}$ & & \\
\hline FEV1 $<50 \%$ pred, $(\mathrm{n}=29)$ & $21(72.4 \%)$ & $8(27.6 \%)$ & 0.000 & $3.8(1.89-7.74)$ \\
\hline FEV1 $\geq 50 \%$ pred, $(n=37)$ & $7(18.9 \%)$ & $30(81.1 \%)$ & & \\
\hline
\end{tabular}

Table 6. Relationship of risk factors with dimensions, function of RV, and probability of $\mathrm{PH}$

\begin{tabular}{|c|c|c|c|c|c|c|}
\hline \multirow{2}{*}{ Risk factor } & \multicolumn{2}{|c|}{ RV dilatation } & \multicolumn{2}{|c|}{ RV dysfunction } & \multicolumn{2}{|c|}{ Probability of $\mathrm{PH}$} \\
\hline & $\mathrm{p}$ & PR $(95 \%$ CI $)$ & $\mathrm{p}$ & PR (95\% CI) & $\mathrm{p}$ & PR $(95 \% \mathrm{CI})$ \\
\hline FEV $<50 \%$ pred & 0.000 & $\begin{array}{c}8.3 \\
(2.03-33.87)\end{array}$ & 0.005 & $\begin{array}{c}11.5 \\
(1.54-85.53)\end{array}$ & 0.000 & $\begin{array}{c}3.8 \\
1.89-7.74\end{array}$ \\
\hline Gender & 1.000 & $\begin{array}{c}0.9 \\
(0.16-5.24)\end{array}$ & 1.000 & & 0.837 & $\begin{array}{c}1.7 \\
(0.31-9.74)\end{array}$ \\
\hline Age & 0.134 & $\begin{array}{c}2.4 \\
(0.86-6.87)\end{array}$ & 0.410 & $\begin{array}{c}2.1 \\
(0.58-7.31)\end{array}$ & 0.410 & $\begin{array}{c}1.3 \\
(0.76-2.46)\end{array}$ \\
\hline Smoking history & 1.000 & & 1.000 & & 1.000 & $\begin{array}{c}1.2 \\
(0.25-6.53)\end{array}$ \\
\hline $\begin{array}{l}\text { History of exacerbations } \geq 2 \\
\text { times in a year }\end{array}$ & 0.000 & $\begin{array}{c}6.3 \\
(2.51-15.59)\end{array}$ & 0.001 & $\begin{array}{c}7.3 \\
(2.13-24.94)\end{array}$ & 0.004 & $\begin{array}{c}3.9 \\
(1.32-11.45)\end{array}$ \\
\hline Hypertension & 1.000 & $\begin{array}{c}1.2 \\
(0.45-2.93)\end{array}$ & 0.726 & $\begin{array}{c}1.5 \\
(0.48-4.85)\end{array}$ & 0.582 & $\begin{array}{c}1.2 \\
(0.72-2.25)\end{array}$ \\
\hline Diabetes mellitus & 0.567 & & 1.000 & & 0.316 & \\
\hline
\end{tabular}

Table 7. Risk factors affecting RV dilatation, RV dysfunction, and probability of HP via multivariate logistic regression analysis

\begin{tabular}{lcccc}
\hline \multicolumn{1}{c}{ Risk factors associated with RV dilatation } & \multirow{2}{*}{ Significance } & \multirow{2}{*}{ Odd ratio } & \multicolumn{2}{c}{ 95\% CI for Exp(B) } \\
\cline { 3 - 5 } FEV1 $<50 \%$ pred & & 5.250 & Lower & Upper \\
History of exacerbations $\geq 2$ times in a year & 0.091 & 5.556 & 1.078 & 28.891 \\
Age $\geq 65$ years old & 0.250 & 2.389 & 0.542 & 10.520 \\
\hline \multirow{2}{*}{ Risk factors associated with RV dysfunction } & \multirow{2}{*}{ Significance } & \multirow{2}{*}{ Odd ratio } & \multicolumn{2}{c}{$95 \%$ CI for Exp(B) } \\
\cline { 4 - 5 } FEV1 <50\% pred & 0.140 & 6.545 & 0.541 & Upper \\
History of exacerbations $\geq 2$ times in a year & 0.001 & 12.185 & 2.641 & 56.232 \\
\multicolumn{2}{|}{ Risk factors associated with probability of PH } & \multirow{2}{*}{ Significance } & \multirow{2}{*}{ Odd ratio } & Lower CI for Exp(B) \\
\hline FEV1 <50\% pred & 0.139 & 3.150 & 0.690 & Upper \\
History of exacerbations $\geq 2$ times in a year & 0.001 & 11.250 & 3.535 & 35.390 \\
\hline
\end{tabular}

COPD is significantly associated with an increase in the probability of $\mathrm{PH}$ with $p=0.000$ (Table 4). The bivariate test showed that in the COPD group with severe degrees of COPD, the probability of $\mathrm{PH}$ was $72.4 \%$ with $p=0.000$ and PR 3.8 (1.89-7.74). This shows that the severity of COPD with an FEV1 <50\% predominantly causes an increase in the probability prevalence of $\mathrm{PH} 3.8$ times more than in the mildmoderate COPD group (Table 5).

Relationship of a risk factor with dimensions, the function of $\mathrm{RV}$, and probability of $\mathrm{PH}$

Bivariate analysis between risk factors and their relationship with the dimensions, function of $\mathrm{RV}$, and probability of $\mathrm{PH}$ found that a history of exacerbations $\geq 2$ times in a year was a factor that significantly influenced the increase in the prevalence of $\mathrm{RV}$ dilation ( $p=0.000$, PR 6.3 (2.51-15.59), RV dysfunction ( $p=$ 0.001 , PR 7.3 (2.13-24.94), and probability of PH ( $p=$ 0.004 , PR 3.9 (1.32-11.45) compared to the group without exacerbations or the number of exacerbations $<2$ times in a year (Table 6).

Logistic regression multivariate analysis of risk factor with dimensions, the function of $R V$, and probability of $\mathbf{P H}$

Variable factors associated with RV dilatation, RV dysfunction, and increased incidence of PH (Table 6) were included in the multivariate logistic regression analysis and it was found that a history of exacerbations 
$\geq 2$ times in a year was the only parameter independently associated with RV dilatation ( $p=0.040$, OR 5.6 (1.07828.635), RV dysfunction ( $p=0.001$, OR 12.2 (2.641$56.217)$, and increased probability of PH ( $p=0.001$, OR $11.2(3.535-35.799)$ (Table 7).

\section{DISCUSSION}

\section{Prevalence of heart failure}

Assessment of right heart failure in this study used an echocardiography modality by assessing the TAPSE parameter to obtain right ventricular systolic function. In this study, it was found that the prevalence of right heart failure was $15.2 \%$ from 66 stable COPD subjects. Putrawan, et al. found a prevalence of right heart failure which was not much different from this study of $11.4 \%$ of 70 stable COPD subjects using the TAPSE parameter. ${ }^{7}$ Basak, et al. also found a decreased prevalence of RV systolic function with a TAPSE value of $16 \%$ in stable COPD patients. A decrease in the value of TAPSE was found to be $4.2 \%$ in GOLD II, $10.3 \%$ in GOLD III, and $37.9 \%$ in GOLD IV. ${ }^{4}$ Tannus-Silva, et al. also found that $16 \%$ of 50 stable COPD patients with a mean of FEV1 value of $37.6 \%( \pm 19.3)$ pred had RV dysfunction using TAPSE values. ${ }^{8}$

It is undeniable that COPD can cause heart failure, especially in the right heart. Hypoxic conditions, chronic hypoxemia, systemic inflammation, atherosclerotic processes, and endothelial dysfunction of the pulmonary artery cause increased pressure in the pulmonary arteries which triggers $\mathrm{PH}$. This condition causes RV to increase its pressure to push blood into the arteries, increase muscle cells, and ultimately cause enlargement of RV. When RV loses its compensatory ability to maintain proper function to push blood into the pulmonary arteries due to high pulmonary vascular pressure, this condition results in right heart failure or cor pulmonary. .9

The prevalence of left heart failure by assessing left ventricular ejection fraction (LVEF) in this study was found to be $7.6 \%$ and there was no statistically significant relationship between the severity of COPD with decreased left ventricular systolic function $(p>$ 0.05). The same results were found by Gupta, et al. who found a decrease in left ventricular systolic function of $7.5 \%$ in 40 stable COPD subjects and Putrawan who found a $5.7 \%$ prevalence of left heart failure in stable COPD subjects. ${ }^{7,10}$ Buklioska-Ilievska D, et al. also found a prevalence of left heart failure by assessing left ventricular systolic function of $5.5 \%$ in 60 COPD patients. $^{11}$

COPD does not directly cause left heart failure as it does in the right heart. However, left heart failure in COPD patients can occur because they have the same risk factors, namely smoking, chronic hypoxia in COPD, local and systemic inflammation that can lead to an increase in atherosclerotic lesions which can lead to ischemic heart disease which leads to congestive heart failure. ${ }^{12}$ The effect of COPD on RV causes changes in the dimensions of RV. This dimensional change causes a shift in the interventricular septum which changes the geometry of LV, thereby reducing left ventricular filling. ${ }^{13}$

In addition, hypoxia and hypercapnia in COPD also trigger the activity of the myocardial sympathetic nervous system, increasing heart rate, causing stress on LV wall, and followed by enlargement of LV which causes the heart to weaken, harden, and reduce the heart's function in pumping blood. This condition, if it continues, will cause left heart failure. ${ }^{14}$

Relationship between lung function and the dimensions, function, and pressure of the heart's ventricles

In this study, it was found that the prevalence of RV dilatation was $22.7 \%$ and the prevalence of $\mathrm{LV}$ dilatation was $19.7 \%$ from 66 stable COPD subjects. Statistical calculations found a significant relationship between the severity of COPD based on GOLD and RV dilatation $(p=0.000)$. Similar results were performed by Mohammed, et al. who found RV dilation in COPD patients by $18 \%$ and LV dilatation by $25 \%$ in COPD patients. ${ }^{15}$ The study also found $44.8 \% \mathrm{RV}$ dilatation in 29 subjects with FEV1 $<50 \%$ prediction and found a significant association between this group and changes in the dimensions of $\operatorname{RV}(p=0.000)$. Sekhar, et al. found a change in RV dimension in subjects with FEV1 $<50 \%$ predictive of $40 \%$. ${ }^{16}$ Pothal, et al. found that $30 \%$ of 80 COPD subjects had RV dilatation with $35.7 \%$ in 28 GOLD III subjects and $87.5 \%$ of 16 GOLD IV subjects. ${ }^{17}$

In this study, it was found that a decrease in RV function based on the TAPSE value was $15.2 \%$ and a decrease in left ventricular function based on an LVEF value of $7.6 \%$ in 66 stable COPD subjects. There was a significant relationship between the severity of COPD with decreased RV function ( $p=0.000)$. Basak, et al. also found a $16 \%$ prevalence of decreased RV systolic function with a distribution of $4.2 \%$ in 24 GOLD II subjects, $10.3 \%$ in 39 GOLD III subjects, and $37.9 \%$ in 29 GOLD IV subjects. ${ }^{4}$ Tannus-Silva, et al. also found 8 subjects $(16 \%)$ of 50 stable COPD patients with a mean FEV1 value of $37.6 \%( \pm 19.3)$ pred who had RV dysfunction using TAPSE values. ${ }^{8}$ Gupta, et al. found a decrease in LV systolic function of $7.5 \%$ in 40 stable COPD patients and Putrawan found a $5.7 \%$ prevalence of LV dysfunction in stable COPD subjects. ${ }^{7,10}$ 
Buklioska-Ilievska D, et al. also found a prevalence of left heart failure by assessing LV systolic dysfunction of $5.5 \%$ in 60 COPD patients. $^{11}$

As previously explained, chronic hypoxia, which is identical in COPD patients, as well as local and systemic inflammation, are responsible for right heart disorders. Chronic hypoxia will cause pulmonary artery vasoconstriction and systemic inflammation will cause endothelial dysfunction. This condition causes intima hyperplasia and pulmonary artery smooth muscle hypertrophy leading to capillary bed damage. This causes an increase in pulmonary artery resistance, leading to $\mathrm{PH}$. $\mathrm{PH}$ will cause an increase in $\mathrm{RV}$ afterload, hence RV myocardial wall pressure increases, which in turn causes RV dilatation and hypertrophy. The function of RV begins to decrease, resulting in right heart failure. Due to dilatation and hypertrophy of RV, $\mathrm{LV}$ is also affected due to ventricular interdependence and a shift in the interventricular septum. This condition causes changes in the dimensions of $\mathrm{LV}$, both dilated and hypertrophied. Left ventricular function begins to decline and cardiac output is reduced, resulting in left heart failure. ${ }^{14}$

The latest guideline issued by ESC/ERS in 2015 stated that diagnosis of PH based on mean pulmonary artery pressure (MPAP) values using echocardiography is no longer recommended. This is because the assessment of the degree of mild or severe $\mathrm{PH}$ by echocardiography does not show the real thing in patient. The use of echocardiography is only limited in assessing the probability or likelihood of developing PH. The parameters used were TR plus other echo images determined by ESC/ERS, such as the ventricle, pulmonary artery, inferior vena cava, and right atrium. Right heart catheterization is the gold standard for diagnosing $\mathrm{PH}{ }^{18}$

In this study, $42.4 \%$ of subjects had a probability of developing PH based on TR parameters. Putrawan, et al. found that $58.6 \%$ of COPD subjects had a probability of incidence of $\mathrm{PH}^{7}$ In this study, it was found that $18.9 \%$ GOLD II, $69.2 \%$ GOLD III, and 100\% GOLD IV experienced TR. This shows that the severity of COPD was significantly associated with an increased incidence of TR ( $p=0.000)$. Jain, et al. found that the incidence of TR in $60 \%$ of stable COPD patients with mild, moderate, severe, and very severe degrees was $58.3 \%$, $60 \%, 60 \%$, and $100 \%$ respectively, and found a significant relationship between the severity of COPD and the incidence of TR $(p=0.000) .{ }^{19} \mathrm{Kaur}$, et al. found that $72 \%$ of COPD subjects experienced TR with a distribution of $57.1 \%$ in GOLD II, $79.3 \%$ in GOLD III, and $100 \%$ in GOLD IV. The study also found a statistically significant positive correlation between TR and the severity of COPD with a spearman's correlation coefficient of +0.387 and $p$-value $=0.005 .^{20}$

There were no studies which linked the severity of COPD with the probability of $\mathrm{PH}$ based on TR parameters. The use of tricuspid valve parameter in assessing the probability of $\mathrm{PH}$ can be used as an early detection tool in stable COPD patients who are suspected of having $\mathrm{PH}$, thus they do not fall into $\mathrm{PH}$ with the involvement of increased pulmonary artery pressure which in turn will lead to cor pulmonary or heart failure right.

Relationship of exacerbation factors with dimensions, function, and right ventricular pressure

The multivariate test in this study found that the exacerbation factor as many as $\geq 2$ times in a year was an independent factor that caused problems in the right heart, namely RV dilation ( $p=0.040$, OR 5.6 (1.07828.635)), RV dysfunction ( $p=0.001$, OR 12.2 (2.641$56.217)$ ), and an increased probability of PH ( $p=0.001$, OR11.2 (3.535-35.799)). Ozben, et al. found that acute exacerbations of COPD significantly lead to an increase in pulmonary artery pressure which can increase RV afterload, resulting in RV systolic dysfunction (OR 9.3 $95 \%$ CI $=1.86-46.68)$, while in LV there was no significant relationship between changes in dimensions or decreased LV function $(p>0.05) .^{21}$ Terzano, et al. also found that COPD patients with a history of exacerbations caused a decrease in TAPSE values by $14 \pm 6 \mathrm{~mm}$ in moderate COPD and by $11.2 \pm 2.4 \mathrm{~mm}$ in severe COPD with $p=0.05 .^{22}$

Repeated exacerbations cause the pulmonary artery pressure to increase, hence the right ventricular tension continues to increase, causing impaired right ventricular function. ${ }^{23,24}$ Medrek, et al. with a retrospective cohort study found that COPD patients with a history or number of exacerbations $>1$ time in a year had an increased incidence of PH with $p=0.0001$ and OR 1.11 (95\% CI = 1.101-1,116) ${ }^{25}$ El-Shabrawy, et $a l$. also found 84 subjects had a history of exacerbations $\geq 2$ times in a year and $64.8 \%$ of 108 COPD subjects influence the incidence of $\mathrm{PH}^{26}$

\section{CONCLUSION}

This study found a significant relationship between the severity of stable COPD based on GOLD with changes in anatomy, function, and right ventricular pressure. Patients with FEV1<50\% pred caused RV dilatation, RV dysfunction, and an increase in the probability of $\mathrm{PH}$. The prevalence of right heart failure based on the TAPSE parameter found in this study was $15.2 \%$ and the prevalence of left heart failure based on 
the ejection fraction (LVEF) found in this study was $7.6 \%$ of 66 COPD subjects. A history of exacerbations with the number of exacerbations $\geq 2$ times in a year is an independent factor that causes RV dilatation, RV dysfunction, and increases the probability of $\mathrm{PH}$.

The use of tricuspid valve parameters in assessing the probability of PH can be used as an early detection tool in all COPD patients suspected of having PH, especially patients with COPD with GOLD III and GOLD IV or FEV1 $<50 \%$ pred and COPD patients who have a history of exacerbations $\geq 2$ times in a year, thus stable COPD patients do not fall in a condition of $\mathrm{PH}$ with the involvement of an increase in pulmonary artery pressure which in turn will lead to cor pulmonary or right heart failure.

\section{Acknowledgments}

The authors are most thankful to the Director of Arifin Achmad General Hospital, Pekanbaru, Riau, Department of Pulmonology and Respiratory Medicine, Department of Cardiology and Vascular Medicine, Department of Radiology, University of Riau, and other health workers who have provided assistance and support in completing this study.

\section{Conflict of Interest}

The author stated there is no conflict of interest in this study.

\section{Funding}

This study was funded by personal expenses.

\section{Authors' Contributions}

Writing manuscript, gathering samples, designing experiments, making tables and figures, interpreting data: AWA. Reviewing and revising, interpreting data, designing experiments: A and FY. Reviewing and revising: DS and Z. All authors have read and agreed to the published version of the manuscript.

\section{REFERENCES}

1. Global Initiative for Chronic Obstructive Lung Disease (GOLD). Global Strategy for the Diagnosis, Management, and Prevention of Chronic Obstructive Pulmonary Disease (2019 Report). Maryland, 2019. Availabe from [WebPage]

2. Indonesia PDP. Penyakit Paru Obstruktif Kronik (PPOK): Diagnosis dan Penatalaksanaan. Jakarta: UI Press, 2016.

3. Choudhury G, Rabinovich R, MacNee W. Comorbidities and Systemic Effects of Chronic Obstructive Pulmonary Disease. Clin Chest Med 2014; 35: 101-130. [CrossRef] [PubMed]
4. Basak S, Mukherjee R, Chowdhury S, et al. Evaluation of Cardiac Function in COPD Patients and Correlation with Disease Severity: A Cross Sectional Study. Asian J Med Sci 2021; 12: 14-19. [CrossRef]

5. Kaushal M, Shah PS, Shah AD, et al. Chronic Obstructive Pulmonary Disease and Cardiac Comorbidities: A Cross-Sectional Study. Lung India; 33. [CrossRef]

6. Jatav VS, Meena SR, Jelia S, et al. Echocardiographic Findings in Chronic Obstructive Pulmonary Disease and Correlation of Right Ventricular Dysfunction with Disease Severity. Int $J$ Adv Med 2017; 4: 476-480. [CrossRef] [PubMed]

7. Putrawan HA. Gambaran Fungsi Jantung pada Pasien Penyakit Paru Obstruktif Kronik Berdasarkan Echochardiography di RSUP Persahabatan. Universitas Indonesia, 2018.

8. Tannus-Silva D, Silva JB, Silva Júnior JL, et al. Right Ventricle Dysfunction Predicts Prognosis in COPD. Eur Respir J 2015; 46: PA663. [CrossRef]

9. Falk JA, Kadiev S, Criner GJ, et al. Cardiac Disease in Chronic Obstructive Pulmonary Disease. Proc Am Thorac Soc 2008; 5: 543-548. [PMC free article]

10. Gupta NK, Agrawal RK, Srivastav AB, et al. Echocardiographic Evaluation of Heart in Chronic Obstructive Pulmonary Disease Patient and Its CoRelation with the Severity of Disease. Lung India 2011; 28: 105-109. [PubMed]

11. Buklioska-Ilievska D, Minov J, KochovskaKamchevska N, et al. Cardiovascular Comorbidity in Patients with Chronic Obstructive Pulmonary Disease: Echocardiography Changes and Their Relation to the Level of Airflow Limitation. Open Access Maced J Med Sci 2019; 7: 3568-3573. [PubMed]

12. Agarwal SK, Heiss G, Barr RG, et al. Airflow Obstruction, Lung Function, and Risk of Incident Heart Failure: The Atherosclerosis Risk in Communities (ARIC) Study. Eur J Heart Fail 2012; 14: 414-422. [PubMed]

13. Piazza G, Goldhaber SZ. The Acutely Decompensated Right Ventricle: Pathways for Diagnosis and Management. Chest 2005; 128: 1836-1852. [PubMed]

14. Portillo K, Abad-Capa J, Ruiz-Manzano J. Chronic Obstructive Pulmonary Disease and Left Ventricle. Arch Bronconeumol 2015; 51: 227-234. [PubMed]

15. Mohammed YM, ElShahid GS, Osman NM, et al. Cardiac Evaluation of Patients with Chronic Obstructive Pulmonary Disease using Echocardiography. Egypt J Bronchol 2019; 13: 1216. [CrossRef]

16. Sekhar GC, Sammaiah P, Bookya K, et al. Study of Cardiovascular Complications in Chronic Obstructive Pulmonary Disease with Reference to ECG and 2D Echocardiography Findings. Am J Pharm Heal Res 2016; 4: 97-111. [GoogleScholar] 
17. Pothal S, Dani P, Manjhi R, et al. Correlation between Chronic Obstructive Pulmonary Disease and Cardiovascular Abnormality: A Crosssectional Study. J Clin Diagnostic Res 2018; 12: 17-21. [CrossRef]

18. Galiè N, Humbert M, Vachiery J-L, et al. 2015 ESC/ERS Guidelines for the Diagnosis and Treatment of Pulmonary Hypertension: The Joint Task Force for the Diagnosis and Treatment of Pulmonary Hypertension of the European Society of Cardiology (ESC) and the European Respiratory Society (ERS): Endor. Eur Heart J 2016; 37: 67119. [PubMed]

19. Jain J, Soni P, Apte S, et al. A Study of Correlation between the Echocardiographic Changes with the Duration and Severity of Chronic Obstructive Pulmonary Disease. J Evol Med Dent Sci 2014; 3: 1997-2002. [CrossRef]

20. Kaur S, Khurana A, Dhoat PS, et al. Cardiac Evaluation of Chronic Obstructive Pulmonary Disease Patients by ECHO and Its Correlation with Different Grades of Severity of Chronic Obstructive Pulmonary Disease. Int J Adv Med 2017; 4: 98-102. [CrossRef]

21. Ozben B, Eryuksel E, Tanrikulu AM, et al. Acute
Exacerbation Impairs Right Ventricular Function in COPD Patients. Hellenic J Cardiol 2015; 56: 324331. [PubMed]

22. Terzano C, Romani S, Gaudio C, et al. Right Heart Functional Changes in the Acute, Hypercapnic Exacerbations of COPD. Biomed Res Int 2014; 2014: 596051. [PubMed]

23. Deshmukh K, Khanna A. Implications of Managing Chronic Obstructive Pulmonary Disease in Cardiovascular Diseases. Tuberc Respir Dis (Seoul) 2021; 84: 35-45. [PubMed]

24. Chaouat A, Naeije R, Weitzenblum E. Pulmonary Hypertension in COPD. Eur Respir J 2008; 32: 1371-1385. [PubMed]

25. Medrek SK, Sharafkhaneh A, Spiegelman AM, et al. Admission for COPD Exacerbation is Associated with the Clinical Diagnosis of Pulmonary Hypertension: Results from a Retrospective Longitudinal Study of a Veteran Population. COPD 2017; 14: 484-489. [PubMed]

26. Elshabrawy M, Eldamanhory A. Study of Cardiovascular Diseases in Hospitalized AECOPD Patients. Egypt J Chest Dis Tuberc; 66. Epub ahead of print 1 December 2016. DOI: 10.1016/j.ejcdt.2016.08.008. [CrossRef] 